\title{
Pharmacological agents in development for diabetic macular edema
}

Mohammad Ali Sadiq', Muhammad Sohail Halim², , Muhammad Hassan², Neil Onghanseng 'rmak Karaca3, Aniruddha Agarwal ${ }^{4}$, Rubbia Afridi ${ }^{2,5}$, Yasir J. Sepah ${ }^{2}$, Diana V. Do ${ }^{2}$ and Quan Dong No ayen ${ }^{2 *}$ (1)

The authors have retracted this article [1] for legal reasons. Therefore the contents of this article are no longer available. The authors have been invited to submit a new version of the article. All authors have agreed to this retraction.

Sadiq MA, Halim MS, Hassan M, et al. Pharmacological agents in development for diabetic macular edema.

\section{Author details}

${ }^{1}$ Department of $\mathrm{G}$. Imology, y, niversity of Louisville, Louisville, KY, USA. 2 Byers Eye Insti te, St? sford University, Palo Alto, CA 94303, USA. ${ }^{3}$ Department of Ophtham. 'yy, Ly University School of Medicine, Izmir, Turkey. ${ }^{4}$ Advanced Eye Cer Department of Ophthalmology, Postgraduate Institute of Medic rducation à a Research (PGIMER), Chandigarh, India. ${ }^{5}$ Ocular Imaging tesu d'Reading Center (OIRRC), Sunnyvale, CA, USA.

Int J Retin Vitr. 2020;6:29. https://doi.org/10.1186/s4094

Received: 5 ' une 2020 Accepted: 29 June 2020 2-020-00234-z.

*Corres, ondence: ndquan@stanford.edu

${ }^{2}$ Byers Eye Institute, Stanford University, Palo Alto, CA 94303, USA

Full list of author information is available at the end of the article

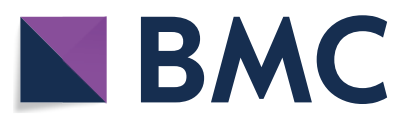

(c) The Author(s) 2020. This article is licensed under a Creative Commons Attribution 4.0 International License, which permits use, sharing, adaptation, distribution and reproduction in any medium or format, as long as you give appropriate credit to the original author(s) and the source, provide a link to the Creative Commons licence, and indicate if changes were made. The images or other third party material in this article are included in the article's Creative Commons licence, unless indicated otherwise in a credit line to the material. If material is not included in the article's Creative Commons licence and your intended use is not permitted by statutory regulation or exceeds the permitted use, you will need to obtain permission directly from the copyright holder. To view a copy of this licence, visit http://creativeco mmons.org/licenses/by/4.0/. The Creative Commons Public Domain Dedication waiver (http://creativecommons.org/publicdomain/ zero/1.0/) applies to the data made available in this article, unless otherwise stated in a credit line to the data. 


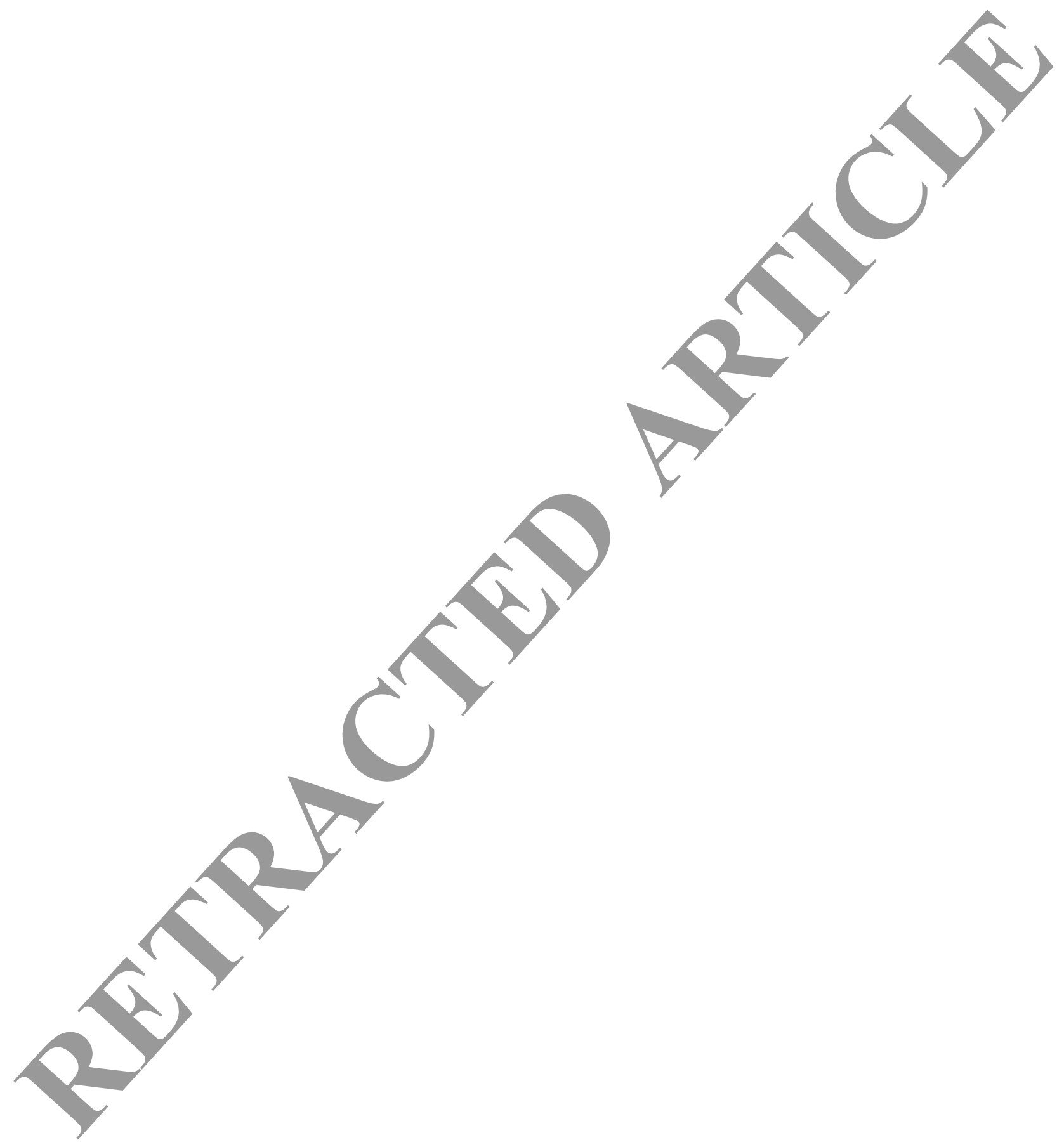




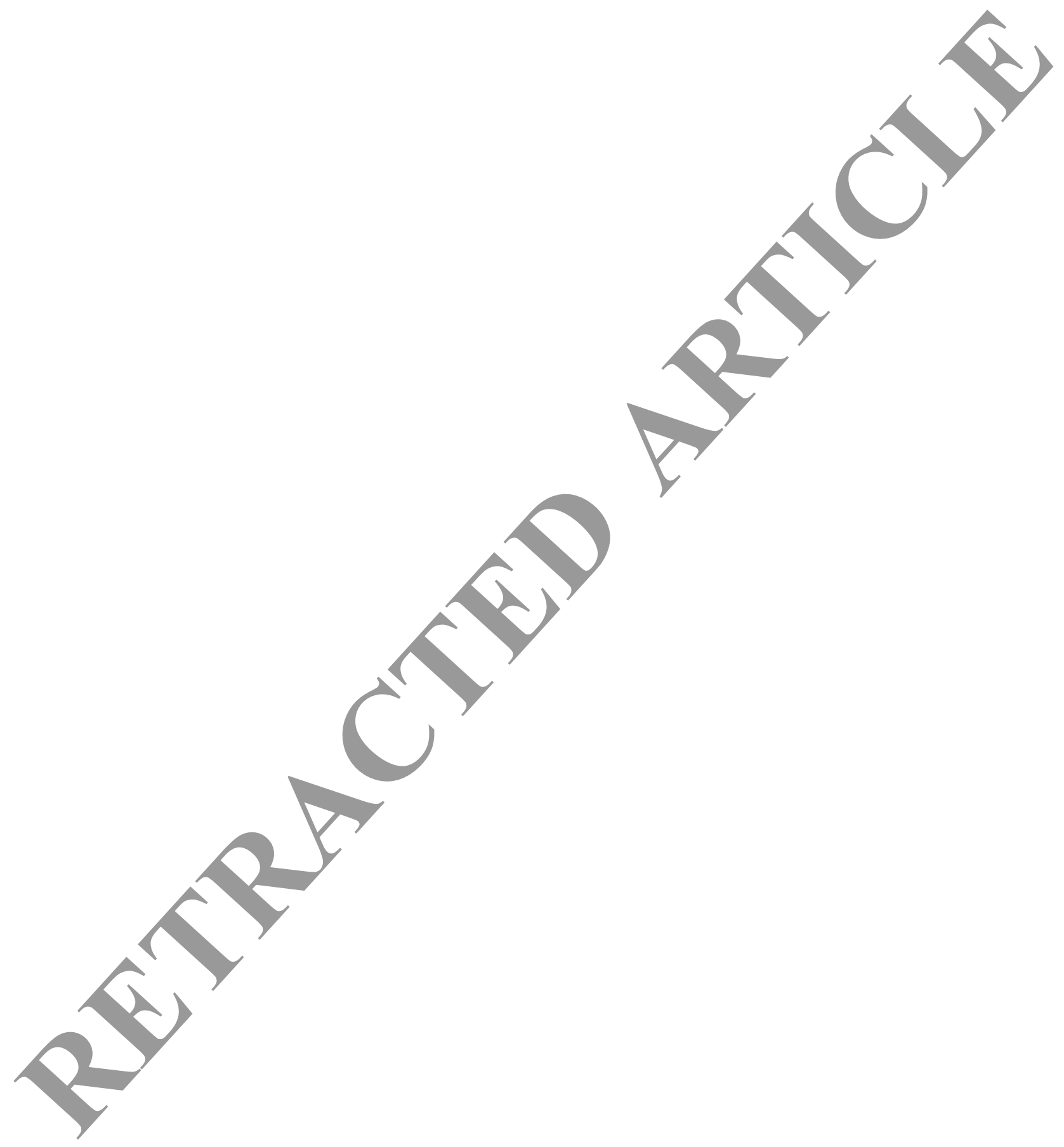




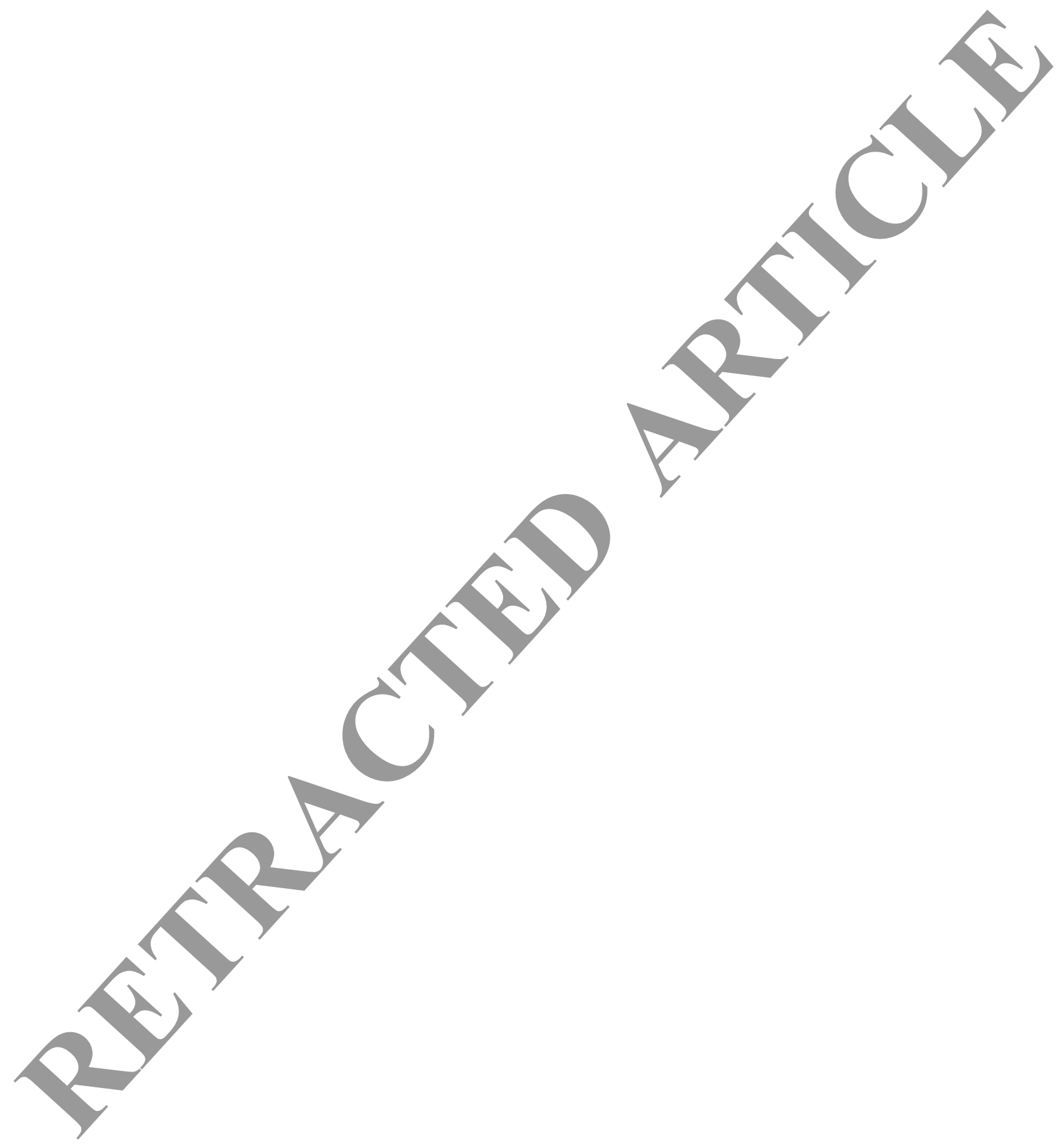




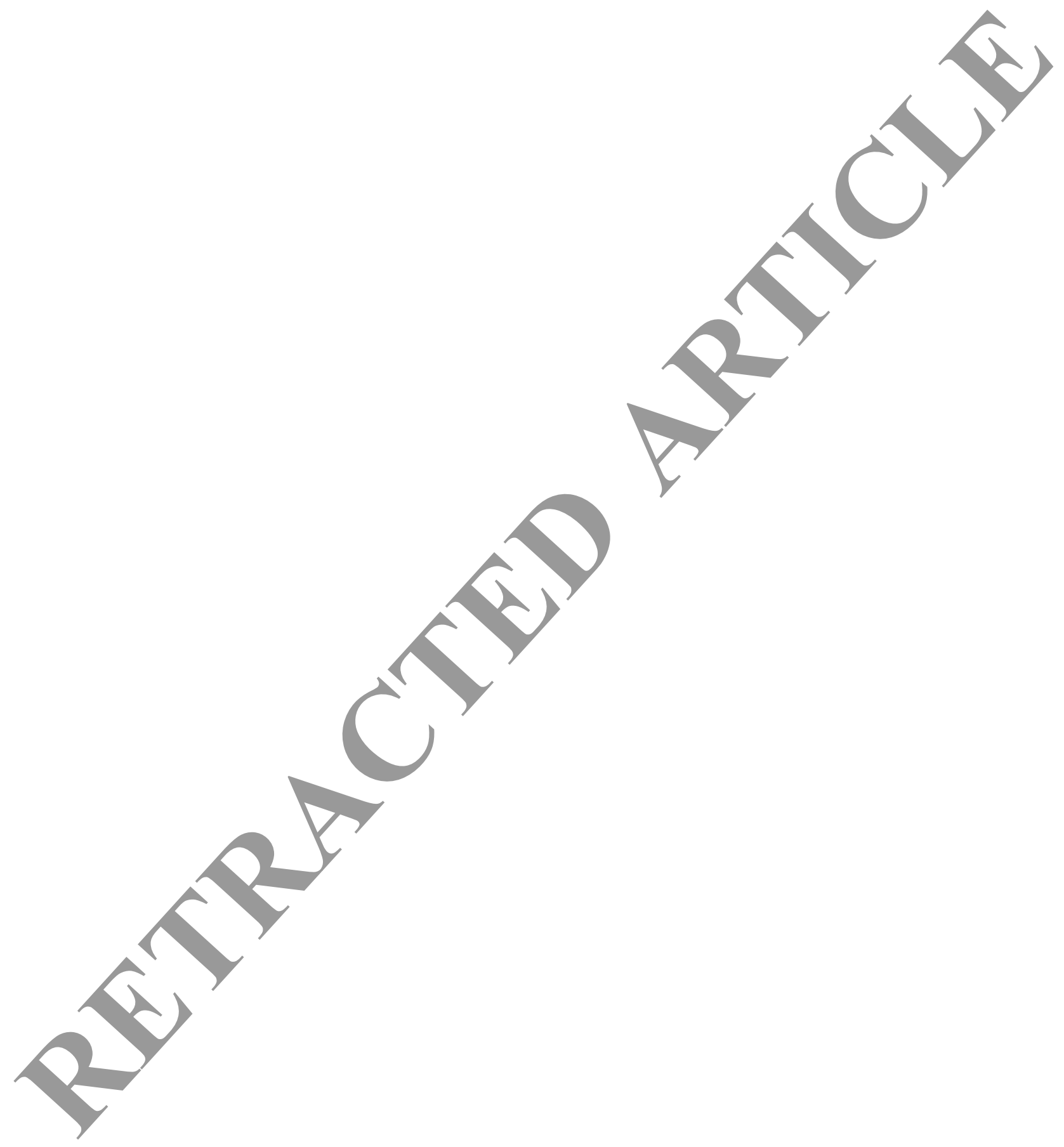




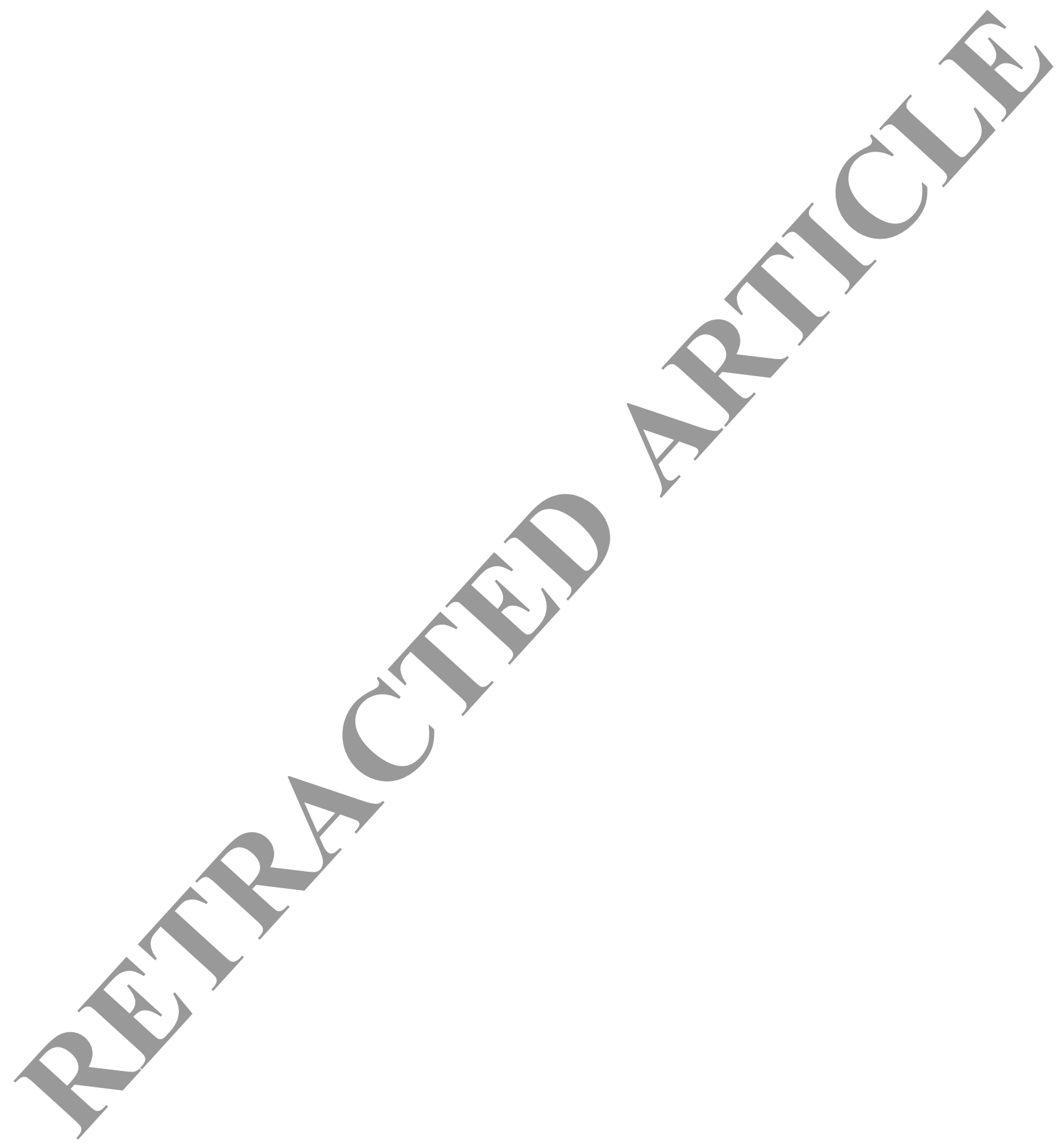




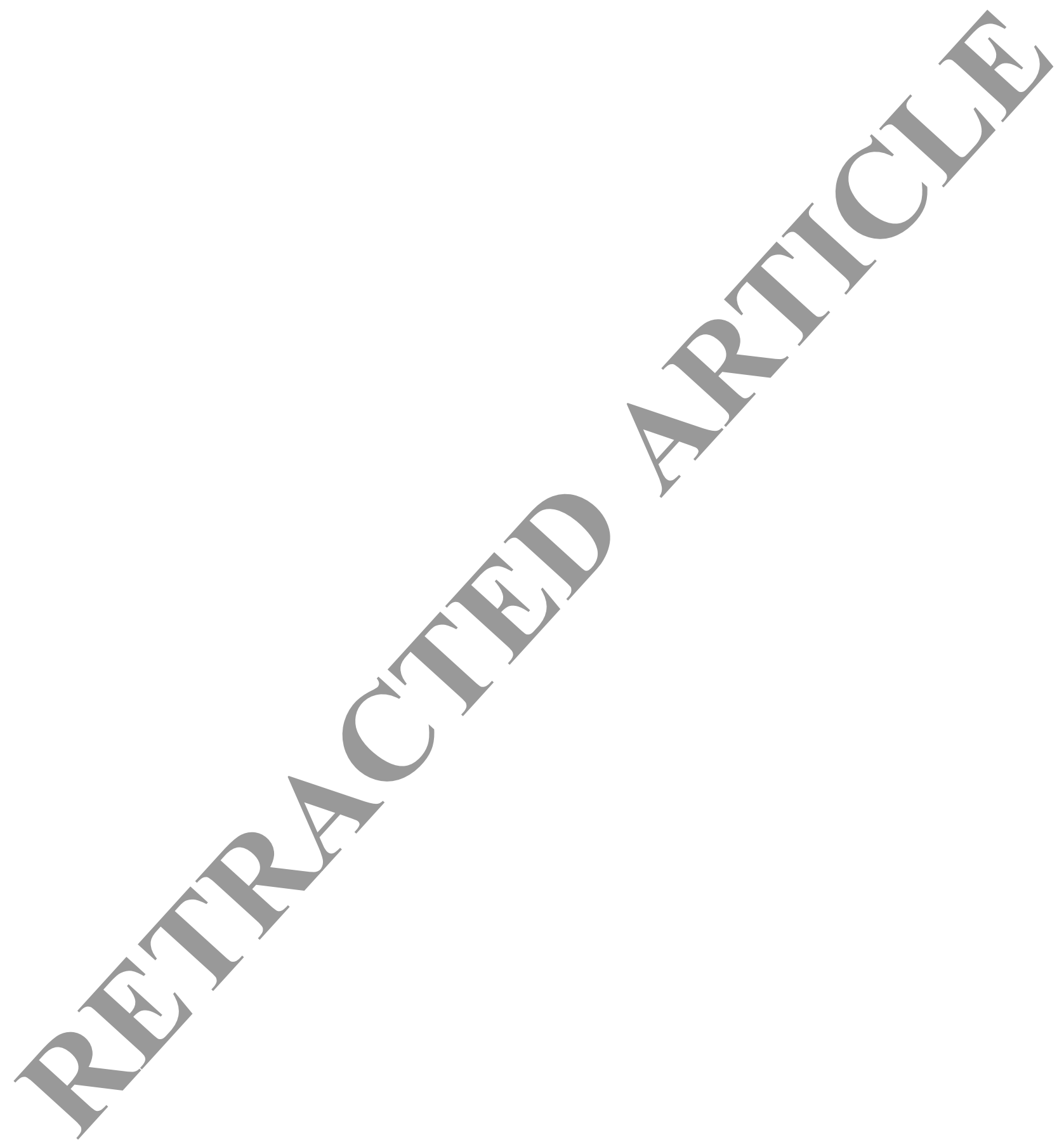




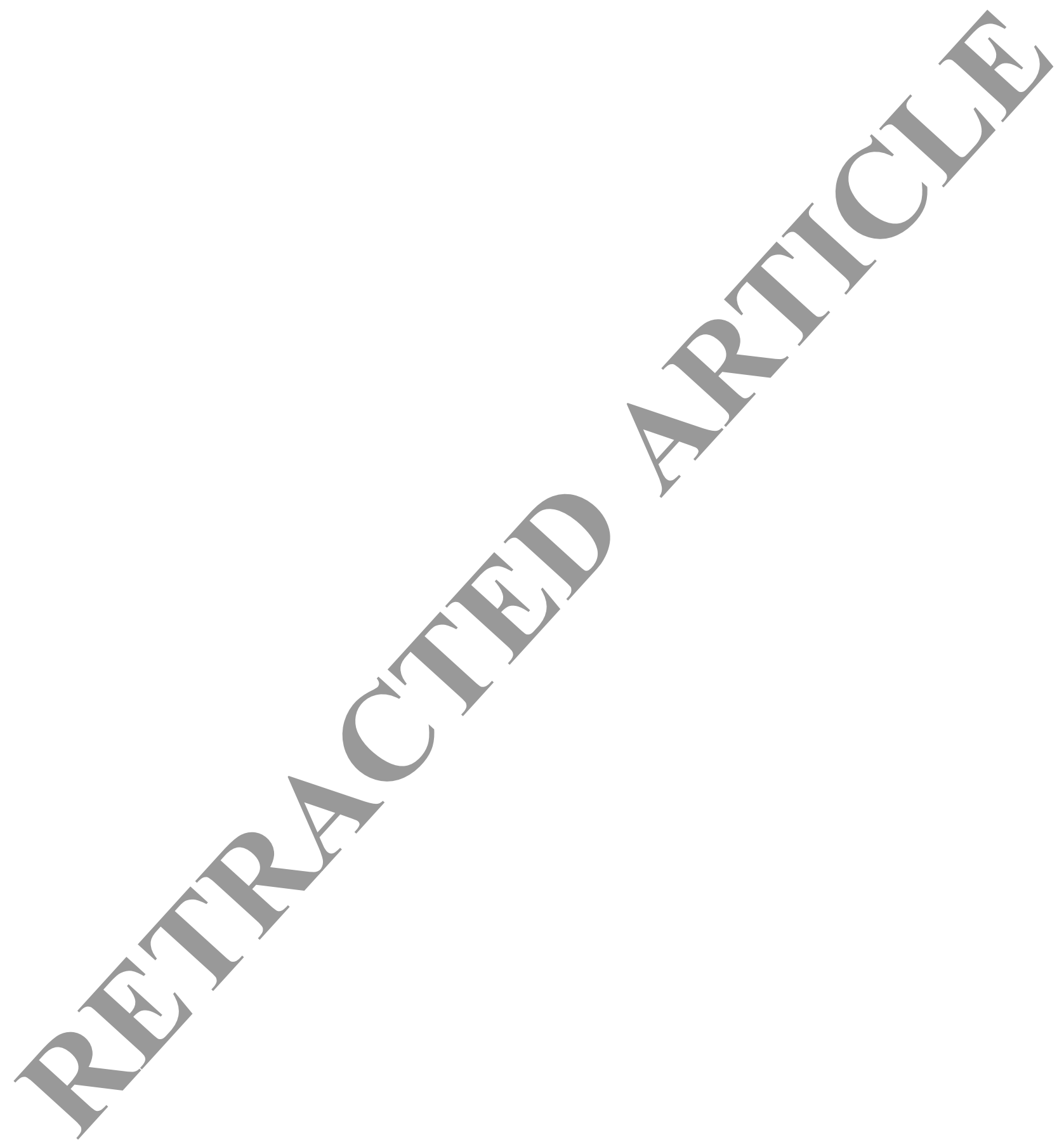




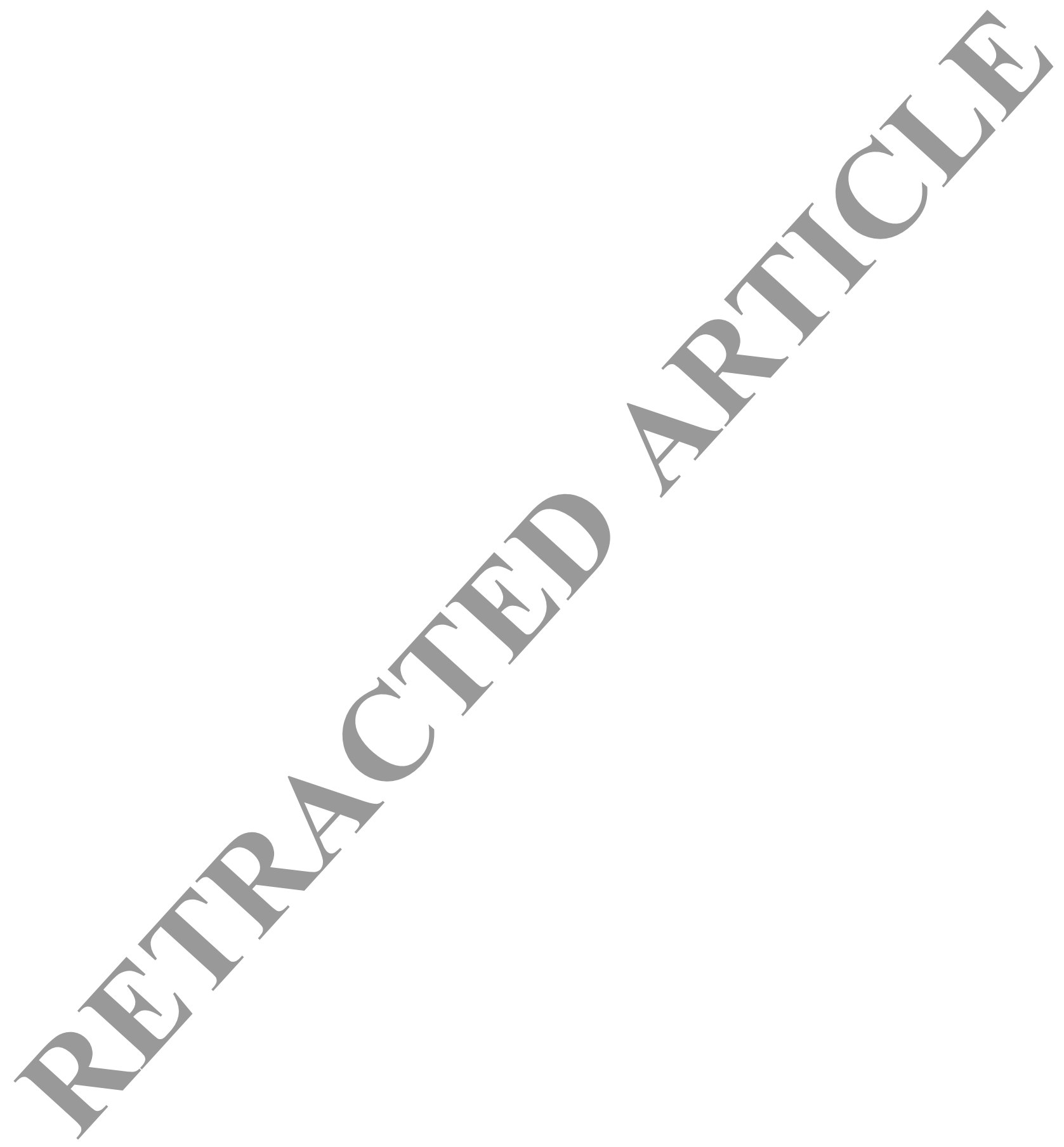




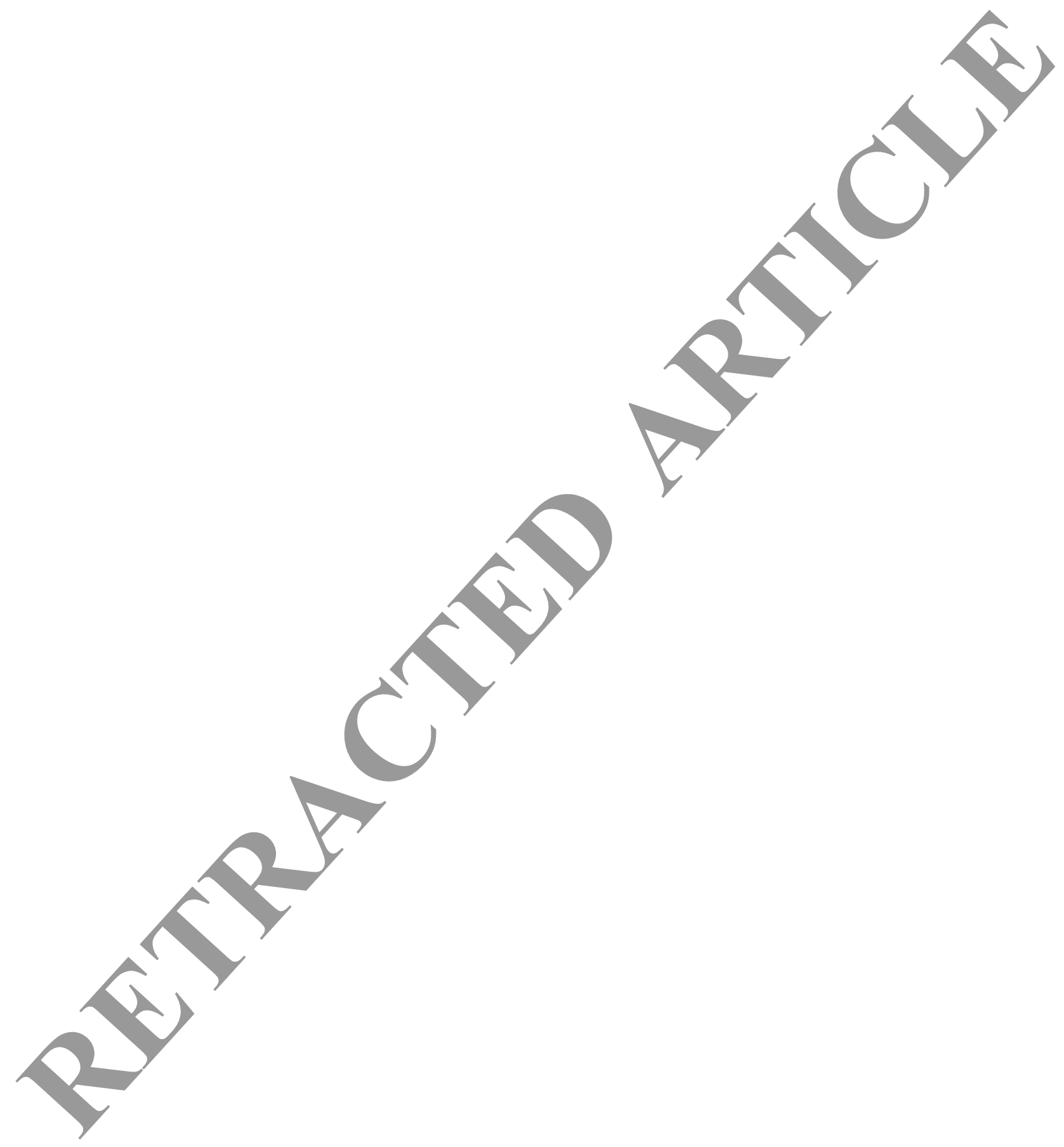




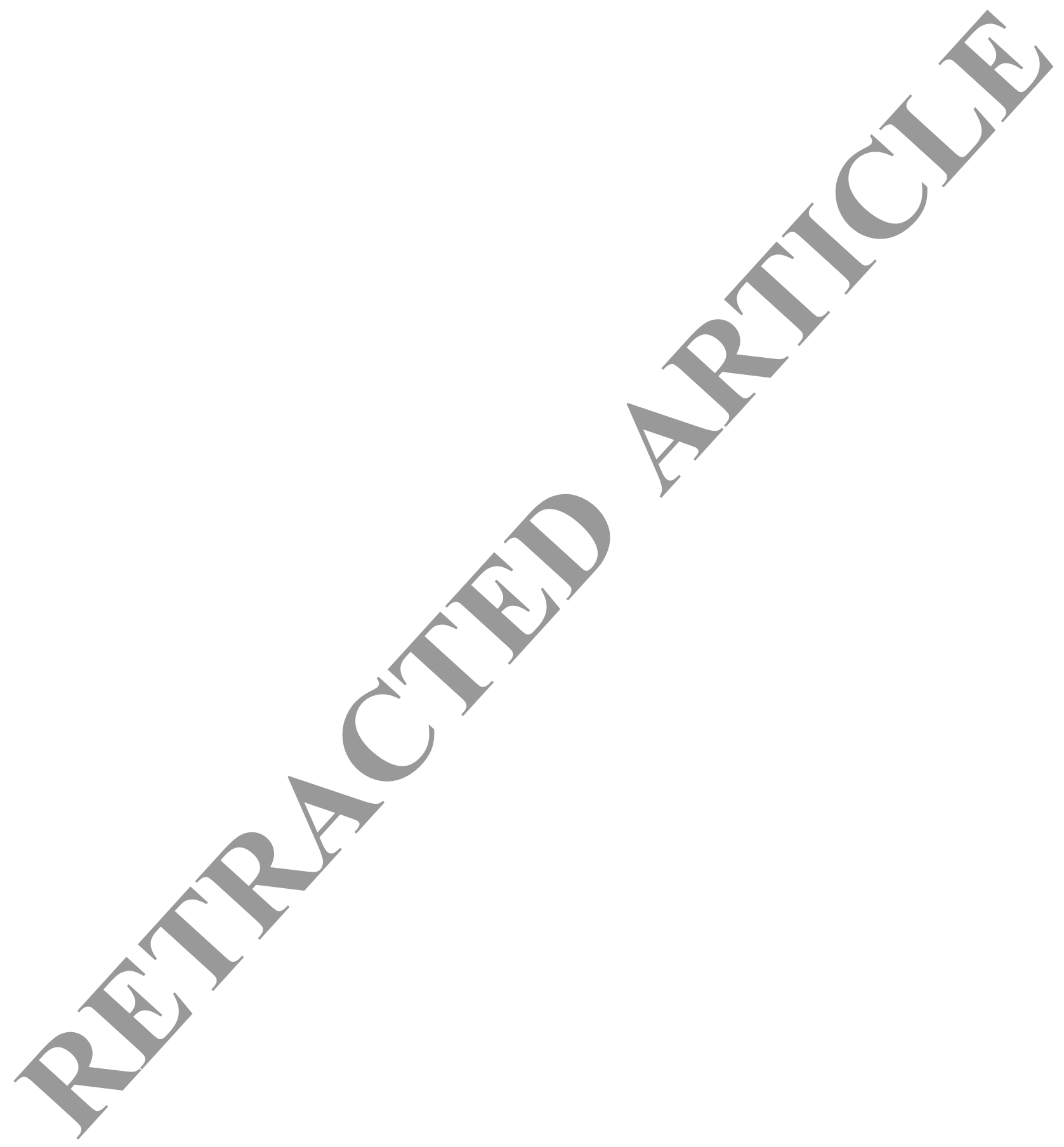

